\title{
LIPGENE food-exchange model for alteration of dietary fat quantity and quality in free-living participants from eight European countries
}

Danielle I. Shaw ${ }^{1}$, Audrey C. Tierney ${ }^{2}$, Sinead McCarthy ${ }^{2}$, Jane Upritchard ${ }^{3}$, Susan Vermunt ${ }^{3}$, Hanne L. Gulseth ${ }^{4,5}$, Christian A. Drevon ${ }^{6}$, Ellen E. Blaak ${ }^{7}$, Wim H. M. Saris ${ }^{7}$, Brita Karlström ${ }^{8}$, Olfa Helal $^{9}$, Catherine Defoort ${ }^{9}$, Raquel Gallego ${ }^{10}$, José López-Miranda ${ }^{10}$, Dominika Siedlecka ${ }^{11}$, Małgorzata Malczewska-Malec ${ }^{11}$, Helen M. Roche ${ }^{2}$ and Julie A. Lovegrove ${ }^{1 *}$

${ }^{1}$ Department of Food Biosciences, University of Reading, Reading RG6 6AP, UK

${ }^{2}$ Nutrigenomics Research Group, UCD Conway Institute of Biomolecular and Biomedical Research, University College Dublin, Belfield, Dublin 4, Republic of Ireland

${ }^{3}$ Unilever Food \& Health Research Institute, Unilever R\&D, Vlaardingen, The Netherlands

${ }^{4}$ Department of Endocrinology, Aker University Hospital, Oslo, Norway

${ }^{5}$ Faculty of Medicine, University of Oslo, Oslo, Norway

${ }^{6}$ Department of Nutrition, Institute of Basic Medical Sciences, Faculty of Medicine, University of Oslo, POB 1046 Blindern, 0316 Oslo, Norway

${ }^{7}$ Department of Human Biology, NUTRIM, Maastricht University, The Netherlands

${ }^{8}$ Department of Public Health and Caring Sciences/Clinical Nutrition and Metabolism, Uppsala University, Uppsala Science Park, SE 75185 Uppsala, Sweden

${ }^{9}$ UMR INSERM 476, Faculté de Médecine Timone, Marseille, France

${ }^{10}$ Reina Sofia University Hospital, School of Medicine, University of Cordoba, Cordoba, Spain

${ }^{11}$ Department of Clinical Biochemistry, Jagiellonian University Medical College, Krakow, Poland

(Received 17 January 2008 - Revised 19 June 2008 - Accepted 24 June 2008 - First published online 5 August 2008)

Controlled human intervention trials are required to confirm the hypothesis that dietary fat quality may influence insulin action. The aim was to develop a food-exchange model, suitable for use in free-living volunteers, to investigate the effects of four experimental diets distinct in fat quantity and quality: high SFA (HSFA); high MUFA (HMUFA) and two low-fat (LF) diets, one supplemented with 1.24 g EPA and DHA/d (LFn-3). A theoretical food-exchange model was developed. The average quantity of exchangeable fat was calculated as the sum of fat provided by added fats (spreads and oils), milk, cheese, biscuits, cakes, buns and pastries using data from the National Diet and Nutrition Survey of UK adults. Most of the exchangeable fat was replaced by specifically designed study foods. Also critical to the model was the use of carbohydrate exchanges to ensure the diets were isoenergetic. Volunteers from eight centres across Europe completed the dietary intervention. Results indicated that compositional targets were largely achieved with significant differences in fat quantity between the high-fat diets (39.9 (SEM 0.6) and 38.9 (SEM 0.51) percentage energy (\%E) from fat for the HSFA and HMUFA diets respectively) and the low-fat diets (29.6 (SEM 0.6) and 29.1 (SEM 0.5) \%E from fat for the LF and LFn-3 diets respectively) and fat quality (17.5 (SEM 0.3) and 10.4 (SEM 0.2) \%E from SFA and 12.7 (SEM 0.3) and 18.7 (SEM 0.4 ) $\%$ E MUFA for the HSFA and HMUFA diets respectively). In conclusion, a robust, flexible food-exchange model was developed and implemented successfully in the LIPGENE dietary intervention trial.

Dietary fat composition: MUFA: SFA: Long-chain $n-3$ PUFA: Food exchange: LIPGENE

The LIPGENE project is a large European, multi-centre project which includes a human intervention trial (486 volunteers at baseline) conducted to compare the impact of different types and amounts of dietary fatty acids on insulin sensitivity. Although the achievement of target dietary intakes is essential to the successful outcome of any controlled dietary intervention study, detailed information on the strategies used to achieve target intakes is rarely provided ${ }^{(1,2)}$. The purpose of the present report is to describe and evaluate the food-exchange model used to design and implement the four experimental diets in the LIPGENE human intervention study. The key objectives of this strategy were: (i) diets were to differ significantly in overall fat intake but remain isoenergetic; (ii) one diet was to be significantly higher in its SFA content compared with

Abbreviations: CHO, carbohydrate; \%E, energy percentage; HMUFA, high-MUFA; HSFA, high-SFA; LF, low-fat; LFn-3, low-fat + DHA + EPA.

* Corresponding author: Dr Julie A. Lovegrove, fax +44 118378 0080, email j.a.lovegrove@reading.ac.uk 
all other diets, another significantly higher in its MUFA content compared with the three other diets; (iii) the effect of long-chain n-3 PUFA supplementation was tested, based on a low-fat background diet. This intervention was designed for use in free-living volunteers from eight centres across Europe, with minimal disruption to their normal dietary habits. The foodexchange model used is described in detail, the achievement of dietary targets evaluated and the problems encountered discussed.

\section{Methods and volunteers}

\section{Study design}

The dietary intervention study had a randomised, parallel design and was carried out at eight European centres (University College Dublin, Republic of Ireland; University of Reading, UK; Aker University Hospital, University of Oslo, Norway; INSERM, Marseille, France; Maastricht University, The Netherlands; Hospital Universitario Reina Sofía, University of Córdoba, Spain; University of Krakow, Poland; Uppsala University, Sweden).

In total, 486 volunteers with the metabolic syndrome (220 male, 266 female) with an average age of 54.5 years (range 35-70 years) started the study across the eight centres. Considered in the present analysis were volunteers who completed the 12-week intervention trial and provided satisfactorily completed food records ( $n$ 411).

Details of the recruitment strategies and volunteer details have been published previously ${ }^{(3)}$. In brief, volunteers were recruited using various methods including use of general practitioner databases, and poster and newspaper advertisements. Initially volunteers were screened over the telephone using a volunteer suitability questionnaire which assessed dairy food consumption, fish consumption and willingness to consume sandwiches during the study, to ensure potential alteration of diets. This was followed up in those fulfilling the inclusion criteria by completion of a health and lifestyle questionnaire, and anthropometric and biochemical tests.

A minimisation procedure was used centrally to randomise volunteers to one of four study diets. The diets differed in fat quantity and quality whilst remaining isoenergetic. Two diets were designed to provide $38 \%$ energy from fat (\% $\mathrm{E}$ from fat): a diet with high SFA levels (HSFA), which was designed to provide about $16 \% \mathrm{E}$ as SFA; a diet with high MUFA levels (HMUFA), designed to provide about $20 \% \mathrm{E}$ from MUFA. The other two diets were low-fat (LF and LFn-3; $28 \% \mathrm{E}$ from fat) with diet LFn-3 including a $1.24 \mathrm{~g} / \mathrm{d}$ supplement of EPA and DHA (ratio 1.4:1, $4 \times 1 \mathrm{~g}$ capsule/d) and diet LF including a control high-oleic acid sunflower-seed oil capsule $(4 \times 1 \mathrm{~g}$ capsule/d). The target fatty acid compositions of the four diets are included in Table 1. Diets were designed to

Table 1. Composition of diets at baseline and end of intervention period, alongside dietary targets* (Mean values with their standard errors)

\begin{tabular}{|c|c|c|c|c|c|c|c|c|}
\hline \multirow[b]{2}{*}{ Completers ( $n$ 411) } & \multicolumn{2}{|c|}{ HSFA ( $n$ 97) } & \multicolumn{2}{|c|}{ HMUFA $(n 111)$} & \multicolumn{2}{|c|}{$\operatorname{LF}(n 104)$} & \multicolumn{2}{|c|}{ LF $n-3$ ( $n$ 99) } \\
\hline & Mean & SEM & Mean & SEM & Mean & SEM & Mean & SEM \\
\hline \multicolumn{9}{|l|}{ Baseline } \\
\hline Energy $(\mathrm{MJ} / \mathrm{d})$ & $8 \cdot 5^{\mathrm{a}}$ & 0.3 & $8 \cdot 7^{\mathrm{a}}$ & 0.3 & $9 \cdot 0^{\mathrm{a}}$ & 0.3 & $9 \cdot 0^{\mathrm{a}}$ & 0.3 \\
\hline$\%$ from fat & $36 \cdot 4^{\mathrm{a}}$ & $0 \cdot 8$ & $35 \cdot 8^{\mathrm{a}}$ & $0 \cdot 6$ & $35 \cdot 9^{\mathrm{a}}$ & $0 \cdot 8$ & $36 \cdot 3^{a}$ & $0 \cdot 8$ \\
\hline$\% E$ from SFA & $12 \cdot 7^{\mathrm{a}}$ & 0.3 & $12 \cdot 3^{a}$ & 0.3 & $11.9^{\mathrm{a}}$ & 0.3 & $12 \cdot 7^{\mathrm{a}}$ & 0.3 \\
\hline$\%$ E from MUFA & $13 \cdot 2^{\mathrm{a}}$ & 0.5 & $13 \cdot 7^{\mathrm{a}}$ & 0.4 & $13 \cdot 6^{\mathrm{a}}$ & 0.5 & $13 \cdot 6^{\mathrm{a}}$ & 0.6 \\
\hline$\%$ from PUFA & $5 \cdot 9^{\mathrm{a}}$ & 0.2 & $5 \cdot 4^{\mathrm{a}}$ & 0.2 & $5 \cdot 8^{\mathrm{a}}$ & 0.3 & $5 \cdot 3^{\mathrm{a}}$ & 0.2 \\
\hline$\% \mathrm{E}$ from $\mathrm{CHO}$ & $43 \cdot 6^{\mathrm{a}}$ & 0.8 & $44.0^{\mathrm{a}}$ & 0.7 & $44.0^{\mathrm{a}}$ & 0.8 & $43 \cdot 7^{\mathrm{a}}$ & $0 \cdot 8$ \\
\hline$\% \mathrm{E}$ from protein & $17 \cdot 8^{\mathrm{a}}$ & 0.4 & $17 \cdot 4^{\mathrm{a}}$ & 0.4 & $17 \cdot 9^{\mathrm{a}}$ & 0.4 & $17 \cdot 4^{\mathrm{a}}$ & 0.3 \\
\hline$\%$ E from alcohol & $2 \cdot 3^{\mathrm{a}}$ & 0.4 & $2 \cdot 8^{\mathrm{a}}$ & 0.4 & $2 \cdot 2^{\mathrm{a}}$ & 0.3 & $2 \cdot 6^{\mathrm{a}}$ & 0.4 \\
\hline Total EPA and DHA $(\mathrm{g} / \mathrm{d}) \dagger$ & $0.29^{a}$ & 0.05 & $0.36^{a}$ & 0.06 & $0.40^{\mathrm{a}}$ & 0.06 & $0.33^{\mathrm{a}}$ & 0.06 \\
\hline$n$ & 78 & & 87 & & 87 & & 85 & \\
\hline \multicolumn{9}{|l|}{ Target } \\
\hline$\%$ from fat & 38 & & 38 & & 28 & & 28 & \\
\hline$\% E$ from SFA & 16 & & 8 & & 8 & & 8 & \\
\hline$\%$ E from MUFA & 12 & & 20 & & 11 & & 11 & \\
\hline$\%$ from PUFA & 6 & & 6 & & 6 & & 6 & \\
\hline Total EPA and DHA $(\mathrm{g} / \mathrm{d})$ & & & & & & & $1 \cdot 24$ & \\
\hline \multicolumn{9}{|l|}{ End of intervention } \\
\hline Energy (MJ/d) & $8 \cdot 7^{\mathrm{a}}$ & 0.3 & $8 \cdot 6^{a}$ & $0 \cdot 3$ & $8 \cdot 2^{\mathrm{a}}$ & 0.3 & $8 \cdot 3^{a}$ & 0.2 \\
\hline$\%$ E from fat & $39.9^{\mathrm{a}}$ & 0.6 & $38.9^{\mathrm{a}}$ & 0.5 & $29 \cdot 6^{\mathrm{b}}$ & 0.6 & $29 \cdot 1^{\mathrm{b}}$ & 0.5 \\
\hline$\% \mathrm{E}$ from SFA & $17 \cdot 5^{\mathrm{a}}$ & 0.3 & $10 \cdot 4^{\mathrm{b}}$ & 0.2 & $8 \cdot 6^{\mathrm{c}}$ & 0.3 & $8 \cdot 7^{\mathrm{c}}$ & 0.3 \\
\hline$\%$ from MUFA & $12 \cdot 7^{\mathrm{a}}$ & 0.3 & $18 \cdot 7^{b}$ & 0.4 & $11 \cdot 8^{\mathrm{a}, \mathrm{c}}$ & 0.3 & $11 \cdot 4^{\mathrm{c}}$ & 0.3 \\
\hline$\%$ from PUFA & $6 \cdot 2^{a, b}$ & 0.2 & $6 \cdot 7^{b}$ & 0.2 & $6 \cdot 0^{a, b}$ & 0.2 & $5 \cdot 7^{a}$ & 0.1 \\
\hline$\% \mathrm{E}$ from $\mathrm{CHO}$ & $41 \cdot 2^{\mathrm{a}}$ & 0.7 & $42 \cdot 0^{a}$ & 0.6 & $49 \cdot 4^{\mathrm{b}}$ & 0.8 & $50 \cdot 2^{\mathrm{b}}$ & 0.7 \\
\hline$\% \mathrm{E}$ from protein & $17 \cdot 4^{\mathrm{a}}$ & 0.4 & $16 \cdot 9^{\mathrm{a}}$ & 0.3 & $19 \cdot 2^{\mathrm{b}}$ & 0.5 & $18 \cdot 3^{\mathrm{a}, \mathrm{b}}$ & 0.4 \\
\hline$\%$ from alcohol & $1 \cdot 6^{\mathrm{a}}$ & 0.3 & $2 \cdot 2^{a}$ & 0.4 & $1 \cdot 8^{\mathrm{a}}$ & 0.4 & $2 \cdot 3^{\mathrm{a}}$ & 0.4 \\
\hline Total EPA and DHA $(\mathrm{g} / \mathrm{d}) \dagger$ & $0.26^{\mathrm{a}}$ & 0.04 & $0.30^{\mathrm{a}}$ & 0.05 & $0.39^{a}$ & 0.06 & $1.6^{\mathrm{b}}$ & 0.06 \\
\hline$n$ & 78 & & 87 & & 86 & & 85 & \\
\hline
\end{tabular}

HSFA, high-SFA; HMUFA, high-MUFA; LF, low-fat; LFn-3, low-fat + DHA + EPA; \%E, percentage energy; CHO, carbohydrate.

$a, b, c$ Mean values within a row with unlike superscript letters were significantly different $(P<0.05)$.

* Differences between diet groups were assessed by repeated-measures analysis using a mixed model.

†Fatty acid compositional breakdown is not available for all subjects due to differences in country-specific analysis programs, so $n$ available for this measure is indicated. 
differ only in SFA and MUFA; PUFA was to be maintained at a similar level across all four diets.

\section{Food-exchange model}

A food-exchange model was developed based on the National Diet and Nutrition Survey of UK adults aged 19-64 years ${ }^{(4,5)}$ and the North/South Ireland Food Consumption Survey ${ }^{(6)}$.

This strategy further developed the method employed by Roche et al. ${ }^{(7)}$ and Nydahl et al. ${ }^{(2)}$ which replaced SFA with MUFA to varying degrees. In the LIPGENE intervention study, the food-exchange model was designed to ensure the target dietary fatty acid compositions of the four diets were achievable in a free-living population across Europe. Mean population intakes (from the National Diet and Nutrition Survey) of total energy, total fat, SFA, MUFA and PUFA for males and females were tabulated separately. This included a breakdown of the major sources of exchangeable dietary fat (Table 2). Exchangeable fat was considered to be that which was not intrinsic within a food product; it could be removed from the diet and replaced with study foods. Although foods such as meat and meat products contribute significantly to the daily intake of fat in many diets, they were not used in the LIPGENE exchange model. The fat within these foods is intrinsic and cannot be manipulated easily to produce comparable products which differ only in fatty acid profile. The amount of exchangeable fat in the average UK diet was calculated as the sum of fat provided by added fats (spreads and oils), milk, cheese, biscuits, cakes, buns and pastries. The total exchangeable fat was subtracted from the National Diet and Nutrition Survey total fat intake to determine the non-modifiable fat intake. This formed the backbone of the food-exchange model onto which specifically designed sources of exchangeable fat were added to create diets of differing fat composition.

The reintroduction of fat involved the use of specifically designed study foods manufactured by Unilever Food \& Health Research Institute (Unilever R\&D, Vlaardingen, The Netherlands). The compositions of the study foods were designed alongside the food-exchange model. Drawing from previous research ${ }^{(1)}$, ideal profiles were established that allowed the theoretical alteration of dietary composition, by the use of food products that were also organoleptically pleasing and without technological limitation. The study foods included spreads, cooking oils, baking fats and mayonnaises. These foods contained fat that was easily manipulated and exchanging these foods within the volunteers' diet had minimal impact on their usual dietary habits. Three types of spreads were available and formulated to be either high in SFA, high in MUFA or low in fat. Each type of spread had two varieties which differed only in salt content to account for the differences in acceptable sensorial properties by volunteers across Europe. Fat products were also provided and used in the manufacture of biscuit products (Fusco Foods, Ltd, Dublin, Republic of Ireland; Santa Marta Food Company, Cordoba, Spain; Zakład Piekarniczy Tost Grondal, Poland). The average nutritional composition of the study foods is shown in Appendix 1. Looders-Croklaan (Wormerveer, The Netherlands) supplied the study capsules used in diets LF and LFn-3.

Inclusion of these modified study foods allowed modification of overall dietary fat composition (Table 3). Also critical to the food-exchange model was the use of carbohydrate (CHO) exchanges to ensure all four diets were isoenergetic. One $\mathrm{CHO}$ exchange was considered as $35 \mathrm{~g}$ complex $\mathrm{CHO}$, for example, slice of brown bread, handful of rice, one potato. In diets HSFA and HMUFA (38\% $\mathrm{E}$ as fat), one $\mathrm{CHO}$ exchange was removed. In diets LF and LFn-3, fat intake was lower than the average National Diet and Nutrition Survey level and therefore two CHO exchanges were added in the exchange model to ensure appropriate energy intake.

The LIPGENE food-exchange model was verified using Irish food consumption survey data ${ }^{(6)}$ and the North/South Ireland Food Consumption databases (www.iuna.net). The food and nutrient intake database from this survey is stored in a disaggregated format with full compositional analyses for each food at every mealtime for $7 \mathrm{~d}$ presented in a relational database. Volunteers with a BMI of $\geq 25 \mathrm{~kg} / \mathrm{m}^{2}$ were randomly selected from the database. The modifiable foods consumed were identified and removed from the diets of each volunteer. The removed foods were replaced with the modified foods and nutrient composition was reanalysed for all four modified diets, demonstrating that the target diets were achievable in a random selection of Irish obese subjects without any change in energy intake.

Table 2. Exchangeable fat intake and its removal ${ }^{*}$

\begin{tabular}{|c|c|c|c|c|c|c|c|c|c|c|}
\hline & \multicolumn{2}{|c|}{$\begin{array}{l}\text { Total energy } \\
(\mathrm{MJ} / \mathrm{d})\end{array}$} & \multicolumn{2}{|c|}{ Total fat $(\mathrm{g} / \mathrm{d})$} & \multicolumn{2}{|c|}{ SFA $(g / d)$} & \multicolumn{2}{|c|}{ MUFA (g/d) } & \multicolumn{2}{|c|}{ PUFA (g/d) } \\
\hline & Male & Female & Male & Female & Male & Female & Male & Female & Male & Female \\
\hline NDNS total intake & $9 \cdot 68$ & $6 \cdot 83$ & $86 \cdot 5$ & $61 \cdot 4$ & $32 \cdot 5$ & $23 \cdot 3$ & $29 \cdot 1$ & $20 \cdot 2$ & $15 \cdot 2$ & $11 \cdot 1$ \\
\hline $\begin{array}{l}\text { Exchangeable fat intake } \\
\text { Added fats and oils }\end{array}$ & & & & & & & & & & 3.3 \\
\hline Added fats: spreads & $\begin{array}{l}0.38 \\
0.39\end{array}$ & $\begin{array}{l}0.26 \\
0.27\end{array}$ & $\begin{array}{l}10 \cdot 0 \\
10 \cdot 4\end{array}$ & $\begin{array}{l}7 \cdot 0 \\
6 \cdot 8\end{array}$ & $\begin{array}{l}0.9 \\
3.9\end{array}$ & $\begin{array}{l}0 \cdot 7 \\
2 \cdot 6\end{array}$ & $\begin{array}{l}3 \cdot 9 \\
3.5\end{array}$ & $\begin{array}{l}2 \cdot 7 \\
2 \cdot 2\end{array}$ & $\begin{array}{l}4 \cdot 7 \\
2 \cdot 3\end{array}$ & $\begin{array}{l}3 \cdot 3 \\
1 \cdot 3\end{array}$ \\
\hline Milk & 0.48 & 0.41 & $4 \cdot 3$ & 3.7 & $2 \cdot 6$ & $2 \cdot 1$ & 1.2 & 0.8 & 0.9 & 0.8 \\
\hline Cheese & 0.29 & 0.21 & $5 \cdot 2$ & 3.7 & $3 \cdot 3$ & $2 \cdot 3$ & 1.2 & 0.8 & 0.3 & 0.2 \\
\hline Biscuits, cakes, buns, pastries & 0.58 & 0.48 & $6 \cdot 1$ & $4 \cdot 3$ & $2 \cdot 6$ & 1.9 & $2 \cdot 0$ & 1.4 & $1 \cdot 1$ & 0.8 \\
\hline Total exchangeable fat intake & $2 \cdot 12$ & 1.63 & $36 \cdot 0$ & $25 \cdot 4$ & $13 \cdot 3$ & $9 \cdot 6$ & $11 \cdot 8$ & 8.0 & $9 \cdot 3$ & $6 \cdot 4$ \\
\hline $\begin{array}{l}\text { NDNS intake - exchangeable fat } \\
\text { (non-modifiable fat intake) }\end{array}$ & $7 \cdot 56$ & $5 \cdot 20$ & $50 \cdot 6$ & $36 \cdot 0$ & $19 \cdot 3$ & $13 \cdot 7$ & $17 \cdot 3$ & $12 \cdot 2$ & $5 \cdot 9$ & $4 \cdot 7$ \\
\hline
\end{tabular}

NDNS, National Diet and Nutrition Survey.

* Intake and contribution to total nutrient intake data extracted from the NDNS and the North/South Ireland Food Consumption Survey ${ }^{(4-6)}$. 
Table 3. Replacement of exchangeable fat with study foods

\begin{tabular}{|c|c|c|c|c|c|c|c|c|c|c|c|c|}
\hline & \multicolumn{2}{|c|}{$\begin{array}{c}\text { Weight of } \\
\text { replacement } \\
\text { fat source }(\mathrm{g} / \mathrm{d})\end{array}$} & \multicolumn{2}{|c|}{$\begin{array}{l}\text { Total energy } \\
(\mathrm{MJ} / \mathrm{d})\end{array}$} & \multicolumn{2}{|c|}{$\begin{array}{c}\text { Total fat } \\
(\mathrm{g} / \mathrm{d})\end{array}$} & \multicolumn{2}{|c|}{$\begin{array}{l}\text { SFA } \\
(g / d)\end{array}$} & \multicolumn{2}{|c|}{$\begin{array}{l}\text { MUFA } \\
(\mathrm{g} / \mathrm{d})\end{array}$} & \multicolumn{2}{|c|}{$\begin{array}{l}\text { PUFA } \\
(\mathrm{g} / \mathrm{d})\end{array}$} \\
\hline & Male & Female & Male & Female & Male & Female & Male & Female & Male & Female & Male & Female \\
\hline $\begin{array}{l}\text { NDNS intake - exchangeable } \\
\text { fat (non-modifiable) }\end{array}$ & & & $7 \cdot 56$ & $5 \cdot 20$ & $50 \cdot 6$ & $36 \cdot 0$ & $19 \cdot 3$ & $13 \cdot 7$ & $17 \cdot 3$ & $12 \cdot 2$ & $5 \cdot 9$ & $4 \cdot 7$ \\
\hline \multicolumn{13}{|l|}{ Diet HSFA } \\
\hline Spread & 20 & 15 & 0.59 & 0.44 & $16 \cdot 0$ & $12 \cdot 0$ & $7 \cdot 9$ & 5.9 & $4 \cdot 1$ & $3 \cdot 1$ & $4 \cdot 0$ & 3.0 \\
\hline Oil replacement & 10 & 6 & 0.37 & 0.22 & $10 \cdot 0$ & $6 \cdot 0$ & 4.8 & $2 \cdot 9$ & $3 \cdot 3$ & $2 \cdot 0$ & 1.8 & $1 \cdot 1$ \\
\hline Biscuit* & 45 & 45 & 0.80 & 0.80 & $8 \cdot 7$ & $8 \cdot 7$ & $4 \cdot 1$ & $4 \cdot 1$ & $2 \cdot 3$ & $2 \cdot 3$ & 1.6 & 1.6 \\
\hline Cheese (full-fat) & 17 & 12 & 0.29 & 0.21 & $5 \cdot 8$ & $4 \cdot 1$ & 3.7 & $2 \cdot 6$ & $1 \cdot 6$ & $1 \cdot 1$ & 0.2 & 0.2 \\
\hline Milk (whole) & 230 & 230 & 0.64 & 0.64 & $9 \cdot 0$ & $9 \cdot 0$ & 5.5 & 5.5 & 2.5 & $2 \cdot 5$ & 0.2 & 0.2 \\
\hline $\mathrm{CHO}$ portion & -35 & -35 & -0.34 & -0.34 & -0.7 & -0.7 & -0.1 & -0.1 & -0.1 & -0.1 & -0.2 & -0.2 \\
\hline Total intake & & & 9.91 & $7 \cdot 17$ & $99 \cdot 3$ & $75 \cdot 0$ & $45 \cdot 2$ & 34.7 & $31 \cdot 1$ & $23 \cdot 1$ & 13.5 & $10 \cdot 6$ \\
\hline$\%$ Total energy & & & & & $37 \cdot 8$ & 39.5 & $17 \cdot 2$ & $18 \cdot 2$ & 11.8 & $12 \cdot 2$ & $5 \cdot 1$ & $5 \cdot 6$ \\
\hline \multicolumn{13}{|l|}{ Diet HMUFA } \\
\hline Spread & 20 & 15 & 0.59 & 0.44 & $16 \cdot 0$ & $12 \cdot 0$ & $3 \cdot 1$ & $2 \cdot 3$ & $9 \cdot 6$ & $7 \cdot 2$ & $3 \cdot 3$ & $2 \cdot 5$ \\
\hline Oil & 10 & 6 & 0.37 & 0.22 & $10 \cdot 0$ & $6 \cdot 0$ & $1 \cdot 6$ & 0.9 & 7.4 & 4.5 & 1.0 & 0.6 \\
\hline Mayonnaise $\mathrm{C} 1$ & 20 & 20 & 0.60 & 0.60 & $16 \cdot 3$ & $16 \cdot 3$ & $2 \cdot 5$ & 2.5 & $12 \cdot 1$ & $12 \cdot 1$ & 1.5 & 1.5 \\
\hline Biscuit* & 45 & 45 & 0.80 & 0.80 & 8.7 & 8.7 & $2 \cdot 4$ & 2.4 & 3.8 & 3.8 & 1.8 & 1.8 \\
\hline Cheese (low-fat) & 17 & 12 & 0.19 & 0.13 & $2 \cdot 6$ & $1 \cdot 8$ & $1 \cdot 6$ & $1 \cdot 1$ & 0.7 & 0.5 & 0.1 & 0.1 \\
\hline Milk (skimmed) & 230 & 230 & 0.32 & 0.32 & 0.2 & 0.2 & 0.2 & 0.2 & 0.0 & 0.0 & 0.0 & 0.0 \\
\hline $\mathrm{CHO}$ portion & -35 & -35 & -0.34 & -0.34 & -0.7 & -0.7 & -0.1 & -0.1 & -0.1 & -0.1 & -0.2 & -0.2 \\
\hline Total intake & & & $10 \cdot 09$ & $7 \cdot 37$ & $103 \cdot 6$ & $80 \cdot 2$ & 30.5 & $23 \cdot 1$ & 50.9 & $40 \cdot 2$ & 13.5 & $11 \cdot 0$ \\
\hline \% Total energy & & & & & 38.7 & 41.0 & 11.4 & 11.8 & $19 \cdot 0$ & $20 \cdot 6$ & $5 \cdot 0$ & $5 \cdot 6$ \\
\hline \multicolumn{13}{|l|}{ Diet LF and LF $n-3$} \\
\hline Spread & 15 & 10 & 0.15 & $0 \cdot 10$ & $4 \cdot 2$ & $2 \cdot 8$ & 0.9 & 0.6 & $2 \cdot 2$ & 1.4 & $1 \cdot 1$ & 0.8 \\
\hline Oil & 6 & 4 & 0.22 & $0 \cdot 15$ & $6 \cdot 0$ & 4.0 & 0.7 & 0.4 & 3.4 & $2 \cdot 2$ & $2 \cdot 0$ & $1 \cdot 3$ \\
\hline Biscuit $^{\star}$ & 22.5 & $22 \cdot 5$ & 0.50 & 0.50 & $7 \cdot 1$ & $7 \cdot 1$ & $1 \cdot 6$ & $1 \cdot 6$ & 3.4 & $3 \cdot 4$ & $1 \cdot 2$ & $1 \cdot 2$ \\
\hline Cheese (low-fat) & 17 & 12 & 0.19 & 0.13 & $2 \cdot 6$ & $1 \cdot 8$ & $1 \cdot 6$ & $1 \cdot 1$ & 0.7 & 0.5 & 0.1 & 0.1 \\
\hline Milk (skimmed) & 230 & 230 & 0.32 & 0.32 & 0.2 & 0.2 & 0.2 & 0.2 & 0.0 & 0.0 & 0.0 & 0.0 \\
\hline $\begin{array}{l}\text { CHO portion } \\
\text { Capsules }\end{array}$ & 70 & 70 & 0.69 & 0.69 & 1.4 & 1.4 & 0.2 & 0.2 & 0.2 & 0.2 & 0.4 & 0.4 \\
\hline Total intake & & & $9 \cdot 63$ & 7.09 & $72 \cdot 1$ & $53 \cdot 3$ & 24.4 & $17 \cdot 9$ & $27 \cdot 2$ & $20 \cdot 0$ & $10 \cdot 7$ & 8.5 \\
\hline$\%$ Total energy & & & & & $28 \cdot 2$ & $28 \cdot 3$ & $9 \cdot 6$ & 9.5 & $10 \cdot 6$ & $10 \cdot 7$ & $4 \cdot 2$ & 4.5 \\
\hline
\end{tabular}

NDNS, National Diet and Nutrition Survey; HSFA, high-SFA; CHO, carbohydrate; HMUFA, high-MUFA; C1, food used in cohort 1; LF, low-fat; LFn-3, low-fat + DHA + EPA.

* The food-exchange model shown is based on a typical study biscuit; the type of biscuit used in the model did not substantially affect the model.

\section{Dietary advice}

Before the start of the intervention period volunteers completed a $3 \mathrm{~d}$ weighed food diary and an extensive FFQ. The pre-intervention food diary was analysed using country-specific food databases to reveal the $\% \mathrm{E}$ from total fat, SFA, MUFA, PUFA and $\mathrm{CHO}$, and total energy intake. This gave an insight into the usual dietary habits and allowed identification of foods to be modified and appropriate snack substitution. At the start of the intervention period each volunteer was provided with a handbook for the diet to which they had been randomised. Trained investigators read through the handbook with each volunteer individually, explaining the food-exchange model. Discussion was encouraged and considerable time was spent ensuring that the concept of food exchanges was understood. Key messages were highlighted in a summary sheet which included a clear table of foods to be removed and those that should be consumed instead. Amounts of food to be eaten were stated by weight and in general household measures. Advice was also provided on foods to choose and those to avoid when eating outside the home. Volunteers were advised that other food components such as fruit and vegetables, meats and drinks should be consumed as normal. The $3 \mathrm{~d}$ food diary completed at baseline was used to illustrate where food exchanges should be made, taking into consideration the individual's habitual food patterns. The investigator also consulted the detailed FFQ from each volunteer to assess eating habits and areas that may not have been highlighted in the food diary. Included in the handbooks were sample recipes to illustrate how to incorporate the study foods within the habitual diet.

Volunteers were told to discontinue the use of any habitually used oils, fats or spreads and to use only those provided by the investigators. Volunteers randomised to diet HSFA were asked to ensure all dairy foods consumed were of the full-fat variety. They were asked to replace one snack product normally consumed with their choice of either a muesli cookie or honey flapjack (diet HSFA varieties) each day. These volunteers were also advised to eat less $\mathrm{CHO}$ (equivalent to one $\mathrm{CHO}$ exchange). It was recommended that they have two small handfuls less breakfast cereal or one less slice of bread, or one less potato than normal every day.

Volunteers randomised to diets HMUFA, LF and LFn-3 were asked to use only low-fat dairy products. Volunteers on diet HMUFA were advised to consume the HMUFA mayonnaise provided every day. If they found this difficult, they were asked to consume a handful of hazelnuts or cashew nuts (high in MUFA) when mayonnaise was not consumed. Volunteers on this diet were also asked to replace one 
normally consumed snack product with their choice of biscuit provided.

In diets $\mathrm{LF}$ and $\mathrm{LF} n-3$, in addition to the dairy recommendations described above, volunteers were asked to reduce their intake of high-fat snacks and encouraged to have only one study biscuit every other day. These volunteers were asked to consume two extra portions of $\mathrm{CHO}$ daily, and to take the supplied capsules daily.

Importantly, flexibility was possible with all diets; for example if spread could not be consumed at the required level every day then a greater consumption of oil was advised.

\section{Food collection and compliance monitoring}

At baseline volunteers were provided with a supply of study foods to last for 2 weeks. Additional study foods were supplied if required, for example if they were used in meals given to other family members. Volunteers collected or were delivered additional study foods every fortnight or when required. At these times a $24 \mathrm{~h}$ recall of the previous day's food intake and a short food-use questionnaire based on the study foods were completed to monitor and motivate volunteers to adhere to the dietary advice. A points system was used to assess the number of food exchanges achieved in the $24 \mathrm{~h}$ recall and additional advice was given if either the $24 \mathrm{~h}$ recall or food-use questionnaire showed inadequate intake of food-exchange options. Volunteers meeting exchange requirements were encouraged to continue in this manner. Body weight was measured at baseline, week 6 and week 12, and at additional weeks if required or requested for monitoring purposes. Further dietary advice was given if weight change from baseline had occurred.

\section{Dietary assessment}

Volunteers were asked to complete $3 \mathrm{~d}$ weighed food diaries at baseline, week 6 and week 12. Weighed food intake over 2 weekdays and 1 weekend day was obtained using scales provided by the investigators. Volunteers were asked to include the food packaging and homemade recipes where possible. Various dietary analysis programs were used across the eight European centres to ensure culturally specific foods were included (Reading, UK: Food Base version 3.1; Dublin, Republic of Ireland: WISP version 3.0; Oslo, Norway: Kostberegningssystem (nutrient calculation software developed at the Department of Nutrition, University of Oslo); INSERM, France: Nutrilog; Maastricht, The Netherlands: Komeet to enter the dietary data and Orion to analyse the data; Jagiellonian University Medical College, Poland: 'Dietitian software'; Cordoba, Spain: Dietsource version 2.0; Uppsala, Sweden: MATs connected to the Swedish Board of Food Administration database for foods). Analysis of individual fatty acid intakes was not available in all programs used; therefore the recorded intakes of EPA and DHA are based on intakes measured in a subgroup of volunteers ( $n$ 336).

\section{Statistical analysis}

SPSS (version 14.0; SPSS, Inc., Chicago, IL, USA) was used in all analyses. Data are presented as mean values with their standard errors. Data that were not normally distributed, as assessed by skewness and kurtosis, were subjected to logarithmic or square-root transformation. The volunteers were included as a factor within a mixed linear model with time entered as a repeated measure as dietary intake was measured at three time points; baseline, mid-intervention (week 6) and at the end of the intervention period (week 12). The fixed effects that were included in the final model were sex, centre, time, diet, diet $\times$ time, diet $\times$ centre, time $\times$ centre and age $\times$ centre; age at baseline was included as a fixed covariate. Significant differences were identified where there was no overlap between $95 \% \mathrm{CI}$; thus in the text and tables, statistical significance refers to $P<0 \cdot 05$.

\section{Results}

\section{Achievement of dietary targets}

There were no significant differences in dietary composition at baseline between the four diet groups (Table 1). During the intervention period there were significant differences in various nutrients between diet groups, with the exception of energy intake which did not differ significantly between diet groups. The data presented in Table 1 is from the week 12 dietary assessment which also reflects intake at week 6 , as over this time there were no significant differences in any nutrient, in any of the diet groups.

During the intervention period, \%E from fat was significantly greater in diets HSFA and HMUFA compared with diets LF and LFn-3. Conversely, \% $\mathrm{E}$ from $\mathrm{CHO}$ was significantly greater in diets LF and LFn-3 compared with diets HSFA and HMUFA. \%E from SFA was significantly greater in diet HSFA than the other three diets. Diet HMUFA also had significantly greater $\% \mathrm{E}$ from SFA than diets LF and LFn-3. Diet HMUFA had significantly greater $\% \mathrm{E}$ from MUFA than the other diets, whilst diet HSFA had significantly greater $\% \mathrm{E}$ from MUFA than diet LFn-3. Finally, \% $\mathrm{E}$ from PUFA was significantly greater in diet HMUFA than in diet LF $n$-3. Intake of EPA and DHA was significantly greater on the LFn-3 diet compared with the other diets.

\section{Achievement of dietary targets by each centre}

Dietary intake at baseline differed significantly between centres (Table 4). Most notable were the significantly higher intakes of $\% \mathrm{E}$ from fat in the Marseille, Cordoba and Krakow centres and with \%E from MUFA also significantly higher in the latter two centres. In addition, significantly higher $\% \mathrm{E}$ from CHO intake was recorded at the Uppsala centre.

Each centre successfully manipulated the habitual diets of their volunteers to achieve intervention diets that were distinct in fat composition. Table 4 shows the composition of diets during the intervention period, as assessed at week 12, for each centre separately. In all centres $\% \mathrm{E}$ from fat was greater in diets HSFA and HMUFA compared with diets LF and LF $n-3$, and this reached the level of statistical significance in five centres. In the other three centres, although there was a distinct trend for reduced $\% \mathrm{E}$ from fat levels in diets $\mathrm{LF}$ and LFn-3 compared with diets HSFA and HMUFA, one of the low-fat diets was not statistically distinct in $\% \mathrm{E}$ from fat compared with one of the higher-fat diets. In all centres $\% \mathrm{E}$ from SFA was significantly greater in diet HSFA than the 
Table 4. Composition of diets at baseline and end of intervention period at each centre*

(Mean values with their standard errors)

\begin{tabular}{|c|c|c|c|c|c|c|c|c|c|c|}
\hline & \multicolumn{2}{|c|}{ Baseline } & \multicolumn{2}{|c|}{ HSFA } & \multicolumn{2}{|c|}{ HMUFA } & \multicolumn{2}{|c|}{ LF } & \multicolumn{2}{|c|}{ LFn-3 } \\
\hline & Mean & SEM & Mean & SEM & Mean & SEM & Mean & SEM & Mean & SEM \\
\hline Dublin $(n)$ & 54 & & 13 & & 15 & & 13 & & 13 & \\
\hline Energy (MJ/d) & $10 \cdot 1^{a}$ & 0.4 & $9 \cdot 8^{a, b}$ & 0.7 & $11 \cdot 0^{\mathrm{a}}$ & 0.8 & $8 \cdot 6^{a, b}$ & 0.9 & $6 \cdot 5^{\mathrm{b}}$ & 0.5 \\
\hline$\%$ from fat & $33 \cdot 5^{\mathrm{a}, \mathrm{b}}$ & $1 \cdot 1$ & $38.5^{a}$ & 0.8 & $37 \cdot 5^{\mathrm{a}}$ & $1 \cdot 3$ & $28 \cdot 6^{b}$ & 1.4 & $29 \cdot 1^{b}$ & 1.5 \\
\hline$\% \mathrm{E}$ as SFA & $12 \cdot 1^{\mathrm{b}, \mathrm{c}}$ & 0.4 & $15 \cdot 4^{\mathrm{a}}$ & 0.6 & $11 \cdot 3^{\mathrm{b}}$ & 0.4 & $9 \cdot 0^{\mathrm{C}}$ & 0.5 & $9 \cdot 6^{b, c}$ & 0.9 \\
\hline$\% \mathrm{E}$ as MUFA & $11 \cdot 5^{\mathrm{a}}$ & 0.4 & $12 \cdot 6^{\mathrm{c}}$ & 0.4 & $15 \cdot 8^{\mathrm{b}}$ & 0.7 & $9 \cdot 8^{\mathrm{a}}$ & 0.5 & $10 \cdot 1^{\mathrm{a}}$ & 0.7 \\
\hline$\%$ E as PUFA & $5 \cdot 6^{a, b}$ & 0.3 & $6 \cdot 5^{\mathrm{a}}$ & 0.4 & $6 \cdot 7^{\mathrm{a}}$ & 0.4 & $5 \cdot 7^{\mathrm{a}}$ & 0.5 & $5 \cdot 3^{\mathrm{a}}$ & 0.3 \\
\hline$\% \mathrm{E}$ as $\mathrm{CHO}$ & $45 \cdot 2^{\mathrm{a}, \mathrm{d}}$ & 1.2 & $42 \cdot 7^{\mathrm{a}}$ & 1.5 & $42 \cdot 2^{\mathrm{a}}$ & $2 \cdot 0$ & $48 \cdot 4^{\mathrm{a}}$ & $2 \cdot 4$ & $48 \cdot 2^{\mathrm{a}}$ & $2 \cdot 1$ \\
\hline$\% \mathrm{E}$ as protein & $17 \cdot 3^{\mathrm{a}, \mathrm{b}, \mathrm{c}}$ & 0.5 & $17 \cdot 2^{\mathrm{a}}$ & $1 \cdot 1$ & $17 \cdot 2^{\mathrm{a}}$ & $1 \cdot 0$ & $19 \cdot 2^{\mathrm{a}}$ & 1.6 & $18 \cdot 2^{a}$ & $1 \cdot 1$ \\
\hline$\% \mathrm{E}$ as alcohol & $3 \cdot 8^{\mathrm{a}, \mathrm{b}}$ & 0.7 & $1 \cdot 7^{\mathrm{a}}$ & 0.7 & $3 \cdot 3^{\mathrm{a}}$ & 1.3 & $3.9^{\mathrm{a}}$ & $2 \cdot 0$ & $4 \cdot 2^{\mathrm{a}}$ & 1.8 \\
\hline Total EPA and DHA $(\mathrm{g} / \mathrm{d})$ & $0 \cdot 14^{\mathrm{b}}$ & 0.05 & $0.04^{\mathrm{a}}$ & 0.01 & $0 \cdot 17^{\mathrm{a}}$ & 0.07 & $0.05^{\mathrm{a}}$ & 0.01 & $1 \cdot 3^{b}$ & 0.05 \\
\hline Reading $(n)$ & 57 & & 14 & & 14 & & 15 & & 14 & \\
\hline Energy $(\mathrm{MJ} / \mathrm{d})$ & $9 \cdot 6^{\mathrm{a}}$ & 0.4 & $9 \cdot 1^{\mathrm{a}}$ & 0.7 & $10 \cdot 1^{\mathrm{a}}$ & 0.7 & $7 \cdot 9^{\mathrm{a}}$ & 0.5 & $8 \cdot 9^{\mathrm{a}}$ & 0.7 \\
\hline$\%$ from fat & $31 \cdot 6^{\mathrm{b}}$ & 0.9 & $37 \cdot 3^{a}$ & $2 \cdot 2$ & $35.9^{a}$ & $1 \cdot 3$ & $24 \cdot 8^{b}$ & $2 \cdot 3$ & $28 \cdot 2^{b}$ & 1.4 \\
\hline$\% \mathrm{E}$ as SFA & $11 \cdot 0^{\mathrm{b}}$ & 0.4 & $16 \cdot 6^{\mathrm{a}}$ & $1 \cdot 1$ & $9 \cdot 5^{\mathrm{b}}$ & 0.6 & $7 \cdot 2^{\mathrm{b}}$ & 0.9 & $8 \cdot 8^{\mathrm{b}}$ & 0.6 \\
\hline$\% \mathrm{E}$ as MUFA & $9 \cdot 6^{\mathrm{b}}$ & 0.3 & $10 \cdot 7^{\mathrm{a}}$ & 0.6 & $15 \cdot 7^{b}$ & 0.6 & $8 \cdot 2^{\mathrm{a}}$ & 0.9 & $9 \cdot 5^{\mathrm{a}}$ & 0.5 \\
\hline$\% E$ as PUFA & $4 \cdot 7^{\mathrm{a}}$ & 0.3 & $5 \cdot 4^{a, b}$ & 0.6 & $6 \cdot 3^{b}$ & 0.5 & $4 \cdot 1^{\mathrm{a}}$ & 0.3 & $4 \cdot 7^{\mathrm{a}, \mathrm{b}}$ & 0.3 \\
\hline$\% \mathrm{E}$ as $\mathrm{CHO}$ & $45 \cdot 9^{c}$ & $1 \cdot 1$ & $40 \cdot 3^{a}$ & $2 \cdot 3$ & $41 \cdot 6^{\mathrm{a}}$ & $2 \cdot 0$ & $49 \cdot 0^{\mathrm{a}}$ & $3 \cdot 7$ & $48 \cdot 4^{\mathrm{a}}$ & $1 \cdot 8$ \\
\hline$\% \mathrm{E}$ as protein & $19 \cdot 5^{\mathrm{C}}$ & 0.8 & $19 \cdot 3^{a, b}$ & 1.5 & $17 \cdot 7^{\mathrm{a}}$ & 1.3 & $23 \cdot 4^{\mathrm{b}}$ & $2 \cdot 0$ & $20 \cdot 2^{a, b}$ & 1.0 \\
\hline$\%$ E as alcohol & $3 \cdot 0^{a, b}$ & 0.6 & $3 \cdot 2^{a}$ & 0.9 & $5 \cdot 1^{\mathrm{a}}$ & 1.7 & $2 \cdot 8^{\mathrm{a}}$ & $1 \cdot 3$ & $3 \cdot 2^{a}$ & $1 \cdot 1$ \\
\hline Total EPA and DHA ( $\mathrm{g} / \mathrm{d})$ & $0.44^{\mathrm{a}, \mathrm{c}}$ & 0.10 & $0.29^{\mathrm{a}}$ & 0.07 & $0.41^{\mathrm{a}}$ & 0.14 & $0.26^{\mathrm{a}}$ & 0.06 & $1.6^{b}$ & 0.15 \\
\hline Oslo $(n)$ & 51 & & 10 & & 14 & & 14 & & 13 & \\
\hline Energy $(\mathrm{MJ} / \mathrm{d})$ & $8 \cdot 8^{\mathrm{a}, \mathrm{b}, \mathrm{c}}$ & 0.4 & $9 \cdot 4^{\mathrm{a}}$ & 0.9 & $8 \cdot 4^{a}$ & 0.7 & $9 \cdot 5^{\mathrm{a}}$ & 1.6 & $8 \cdot 8^{a}$ & 0.7 \\
\hline$\%$ from fat & $35 \cdot 7^{\mathrm{a}, \mathrm{c}}$ & 0.9 & $40 \cdot 9^{\mathrm{a}}$ & $2 \cdot 8$ & $40 \cdot 4^{\mathrm{a}}$ & 1.9 & $33 \cdot 4^{\mathrm{a}, \mathrm{b}}$ & 1.5 & $31.4^{\mathrm{b}}$ & 1.6 \\
\hline$\% \mathrm{E}$ as SFA & $13 \cdot 8^{\mathrm{a}}$ & 0.5 & $19 \cdot 0^{\mathrm{a}}$ & 1.5 & $11 \cdot 3^{\mathrm{b}}$ & 0.8 & $10 \cdot 4^{b}$ & 0.6 & $10 \cdot 2^{\mathrm{b}}$ & $0 \cdot 8$ \\
\hline$\%$ as MUFA & $12 \cdot 4^{\mathrm{a}}$ & 0.4 & $12 \cdot 8^{a}$ & 0.9 & $19 \cdot 3^{b}$ & $1 \cdot 2$ & $13 \cdot 0^{\mathrm{a}}$ & 0.6 & $12 \cdot 5^{a}$ & 0.9 \\
\hline$\%$ E as PUFA & $6 \cdot 7^{\mathrm{c}}$ & 0.3 & $6 \cdot 4^{\mathrm{a}}$ & 0.6 & $7 \cdot 3^{\mathrm{a}}$ & 0.5 & $7 \cdot 2^{\mathrm{a}}$ & 0.4 & $6 \cdot 2^{\mathrm{a}}$ & 0.4 \\
\hline$\% \mathrm{E}$ as $\mathrm{CHO}$ & $44 \cdot 0^{\mathrm{a}, \mathrm{b}}$ & 0.9 & $41 \cdot 7^{\mathrm{a}, \mathrm{b}}$ & $2 \cdot 4$ & $39 \cdot 5^{\mathrm{a}}$ & 1.8 & $46 \cdot 8^{\mathrm{b}}$ & 1.7 & $49 \cdot 4^{\mathrm{b}}$ & 1.8 \\
\hline$\% \mathrm{E}$ as protein & $18 \cdot 2^{\mathrm{a}, \mathrm{c}}$ & 0.5 & $16 \cdot 7^{\mathrm{a}}$ & $1 \cdot 1$ & $16 \cdot 5^{a}$ & 0.8 & $19 \cdot 0^{\mathrm{a}}$ & 0.7 & $17 \cdot 7^{\mathrm{a}}$ & 0.9 \\
\hline$\%$ E as alcohol & $2 \cdot 1^{a, b}$ & 0.4 & $1 \cdot 0^{\mathrm{a}, \mathrm{b}}$ & 0.4 & $3 \cdot 8^{\mathrm{a}}$ & 0.9 & $1.0^{\mathrm{b}}$ & 0.5 & $1 \cdot 8^{\mathrm{a}, \mathrm{b}}$ & 0.7 \\
\hline Total EPA and DHA (g/d) & $0.61^{c}$ & 0.08 & $0.38^{a}$ & $0 \cdot 10$ & $0.55^{\mathrm{a}}$ & 0.2 & $0.84^{a}$ & 0.2 & $2 \cdot 1^{b}$ & 0.2 \\
\hline Marseille $(n)$ & 38 & & 8 & & 11 & & 9 & & 10 & \\
\hline Energy $(\mathrm{MJ} / \mathrm{d})$ & $7 \cdot 7^{\mathrm{b}, \mathrm{c}}$ & 0.3 & $8 \cdot 0^{\mathrm{a}}$ & 0.4 & $6 \cdot 3^{\mathrm{a}}$ & 0.4 & $8 \cdot 0^{\mathrm{a}}$ & $0 \cdot 8$ & $8 \cdot 0^{\mathrm{a}}$ & 0.7 \\
\hline$\%$ E from fat & $37 \cdot 7^{\mathrm{c}}$ & $1 \cdot 1$ & $40 \cdot 9^{\mathrm{a}}$ & $2 \cdot 2$ & $36 \cdot 9^{\mathrm{a}}$ & $1 \cdot 2$ & $29 \cdot 1^{\mathrm{b}}$ & 0.6 & $28 \cdot 9^{\mathrm{b}}$ & 0.9 \\
\hline$\% \mathrm{E}$ as SFA & $13 \cdot 5^{\mathrm{a}}$ & 0.6 & $18 \cdot 2^{\mathrm{a}}$ & 1.2 & $8 \cdot 6^{\mathrm{b}}$ & 0.3 & $7 \cdot 1^{\mathrm{b}}$ & 0.4 & $7 \cdot 6^{\mathrm{b}}$ & 0.5 \\
\hline$\% \mathrm{E}$ as MUFA & $12 \cdot 1^{\mathrm{a}}$ & 0.6 & $12 \cdot 8^{\mathrm{a}}$ & 1.2 & $18 \cdot 8^{\mathrm{b}}$ & $1 \cdot 1$ & $12 \cdot 3^{\mathrm{a}}$ & 0.5 & $11.9^{\mathrm{a}}$ & 0.4 \\
\hline$\% E$ as PUFA & $4 \cdot 8^{\mathrm{a}}$ & 0.4 & $5 \cdot 9^{\mathrm{a}}$ & 0.3 & $6 \cdot 2^{\mathrm{a}}$ & 0.4 & $6 \cdot 3^{\mathrm{a}}$ & 0.3 & $6 \cdot 5^{\mathrm{a}}$ & $0 \cdot 2$ \\
\hline$\% \mathrm{E}$ as $\mathrm{CHO}$ & $41 \cdot 8^{\mathrm{b}, \mathrm{c}}$ & $1 \cdot 1$ & $38.0^{\mathrm{a}}$ & 2.5 & $44 \cdot 5^{\mathrm{a}}$ & 1.6 & $52.9^{b}$ & 1.6 & $53 \cdot 3^{\mathrm{b}}$ & $1 \cdot 1$ \\
\hline$\% \mathrm{E}$ as protein & $18 \cdot 9^{\mathrm{a}, \mathrm{c}}$ & 0.7 & $21 \cdot 2^{\mathrm{a}}$ & 1.3 & $18 \cdot 2^{a, b}$ & 0.7 & $17 \cdot 0^{\mathrm{b}}$ & $1 \cdot 2$ & $16 \cdot 9^{b}$ & 0.3 \\
\hline$\%$ E as alcohol & $1 \cdot 9^{\mathrm{a}, \mathrm{b}}$ & 0.5 & $0.5^{\mathrm{a}}$ & 0.4 & $0.4^{\mathrm{a}}$ & 0.4 & $1 \cdot 1^{\mathrm{a}}$ & 0.7 & $1 \cdot 0^{\mathrm{a}}$ & 0.9 \\
\hline Total EPA and DHA $(\mathrm{g} / \mathrm{d}) \dagger$ & $0 \cdot 27^{a, b}$ & 0.11 & $0 \cdot 14^{a}$ & 0.05 & $0.08^{a}$ & 0.03 & $0 \cdot 12^{\mathrm{a}}$ & $0 \cdot 10$ & $1 \cdot 41^{\mathrm{b}}$ & 0.09 \\
\hline$n$ & 25 & & 5 & & 7 & & 6 & & 9 & \\
\hline Maastricht $(n)$ & 49 & & 14 & & 12 & & 11 & & 12 & \\
\hline Energy $(\mathrm{MJ} / \mathrm{d})$ & $9 \cdot 4^{\mathrm{a}, \mathrm{b}, \mathrm{c}}$ & 0.4 & $8 \cdot 7^{\mathrm{a}}$ & 0.6 & $9 \cdot 3^{\mathrm{a}}$ & 0.5 & $8.9^{\mathrm{a}}$ & 0.7 & $8 \cdot 9^{\mathrm{a}}$ & 0.6 \\
\hline$\%$ from fat & $35 \cdot 0^{a, b, c}$ & 1.0 & $40 \cdot 6^{\mathrm{a}}$ & 1.5 & $40 \cdot 2^{\mathrm{a}}$ & 1.4 & $29 \cdot 9^{\mathrm{b}}$ & 1.6 & $28 \cdot 2^{\mathrm{b}}$ & 1.0 \\
\hline$\% \mathrm{E}$ as SFA & $12 \cdot 9^{\mathrm{a}, \mathrm{c}}$ & 0.4 & $17 \cdot 9^{a}$ & 0.6 & $10 \cdot 8^{b}$ & 0.5 & $9 \cdot 1^{\mathrm{b}}$ & 0.6 & $8 \cdot 8^{b}$ & 0.4 \\
\hline$\% \mathrm{E}$ as MUFA & $11 \cdot 1^{a, b}$ & 0.4 & $12 \cdot 6^{\mathrm{a}}$ & 0.7 & $18 \cdot 6^{\mathrm{b}}$ & 0.7 & $11 \cdot 8^{\mathrm{a}}$ & 0.8 & $10 \cdot 5^{\mathrm{a}}$ & 0.5 \\
\hline$\% E$ as PUFA & $7 \cdot 2^{\mathrm{C}}$ & 0.4 & $7 \cdot 0^{a, b}$ & 0.4 & $8 \cdot 5^{\mathrm{b}}$ & 0.5 & $6 \cdot 5^{a, b}$ & 0.4 & $6 \cdot 3^{a}$ & 0.4 \\
\hline$\% \mathrm{E}$ as $\mathrm{CHO}$ & $44 \cdot 6^{a, b}$ & $1 \cdot 0$ & $43 \cdot 0^{a}$ & $1 \cdot 6$ & $41 \cdot 7^{\mathrm{a}}$ & $1 \cdot 7$ & $49 \cdot 7^{b}$ & 1.8 & $50 \cdot 6^{\mathrm{b}}$ & $2 \cdot 0$ \\
\hline$\% \mathrm{E}$ as protein & $16 \cdot 2^{b}$ & 0.4 & $14 \cdot 4^{\mathrm{a}}$ & 0.5 & $15 \cdot 7^{\mathrm{a}}$ & 0.6 & $16 \cdot 8^{\mathrm{a}}$ & 0.8 & $16 \cdot 8^{\mathrm{a}}$ & $1 \cdot 1$ \\
\hline$\%$ E as alcohol & $4 \cdot 2^{\mathrm{a}}$ & 0.7 & $2 \cdot 1^{\mathrm{a}}$ & 0.8 & $2 \cdot 5^{\mathrm{a}}$ & 0.9 & $3 \cdot 8^{\mathrm{a}}$ & $1 \cdot 1$ & $4 \cdot 7^{\mathrm{a}}$ & 1.6 \\
\hline Total EPA and DHA (g/d) & $0 \cdot 15^{\mathrm{b}}$ & 0.05 & $0.14^{\mathrm{a}}$ & 0.08 & $0.07^{\mathrm{a}}$ & 0.04 & $0.15^{\mathrm{a}}$ & 0.07 & $1.34^{\mathrm{b}}$ & 0.07 \\
\hline Cordoba $(n)$ & 75 & & 17 & & 18 & & 20 & & 20 & \\
\hline Energy $(\mathrm{MJ} / \mathrm{d})$ & $8 \cdot 5^{\mathrm{a}, \mathrm{b}, \mathrm{c}}$ & 0.2 & $8 \cdot 2^{a}$ & 0.4 & $7 \cdot 7^{\mathrm{a}}$ & 0.4 & $7 \cdot 7^{\mathrm{a}}$ & 0.4 & $9 \cdot 2^{a}$ & 0.5 \\
\hline$\%$ from fat & $43 \cdot 2^{\mathrm{d}}$ & 0.7 & $40 \cdot 3^{a}$ & 0.5 & $40 \cdot 2^{a}$ & 0.7 & $27 \cdot 1^{\mathrm{b}}$ & 0.5 & $26 \cdot 5^{\mathrm{b}}$ & 0.5 \\
\hline$\% \mathrm{E}$ as SFA & $11 \cdot 1^{\mathrm{b}}$ & 0.2 & $17 \cdot 9^{\mathrm{a}}$ & 0.3 & $9 \cdot 1^{\mathrm{b}}$ & 0.4 & $6 \cdot 6^{\mathrm{c}}$ & 0.3 & $6 \cdot 4^{\mathrm{C}}$ & 0.3 \\
\hline$\% E$ as MUFA & $21 \cdot 4^{\mathrm{C}}$ & 0.4 & $12 \cdot 8^{\mathrm{c}}$ & 0.3 & $21 \cdot 1^{\mathrm{b}}$ & 0.4 & $11 \cdot 5^{\mathrm{a}}$ & 0.3 & $11 \cdot 1^{\mathrm{a}}$ & 0.3 \\
\hline$\% E$ as PUFA & $4 \cdot 6^{\mathrm{a}}$ & 0.1 & $6 \cdot 1^{\mathrm{a}}$ & 0.3 & $5 \cdot 7^{\mathrm{a}}$ & 0.2 & $5 \cdot 3^{\mathrm{a}}$ & 0.2 & $5 \cdot 0^{\mathrm{a}}$ & 0.2 \\
\hline$\% \mathrm{E}$ as $\mathrm{CHO}$ & $38 \cdot 5^{\mathrm{c}}$ & 0.7 & $38 \cdot 3^{\mathrm{a}}$ & 1.0 & $40 \cdot 7^{\mathrm{a}}$ & 1.0 & $51 \cdot 2^{\mathrm{b}}$ & $1 \cdot 1$ & $54 \cdot 1^{\mathrm{b}}$ & 0.9 \\
\hline$\% \mathrm{E}$ as protein & $17 \cdot 1^{a, b}$ & 0.3 & $19 \cdot 2^{a}$ & 0.7 & $19 \cdot 2^{a}$ & 0.7 & $21 \cdot 2^{b}$ & 1.0 & $18 \cdot 8^{a, b}$ & 0.6 \\
\hline$\%$ E as alcohol & $1 \cdot 7^{\mathrm{a}, \mathrm{b}}$ & 0.3 & $2 \cdot 2^{\mathrm{a}}$ & 0.8 & $0 \cdot 3^{\mathrm{a}}$ & 0.2 & $0.6^{\mathrm{a}}$ & 0.3 & $0.6^{\mathrm{a}}$ & 0.3 \\
\hline Total EPA and DHA (g/d) & $0.40^{\mathrm{a}, \mathrm{c}}$ & 0.04 & $0.42^{\mathrm{a}}$ & 0.10 & $0.41^{\mathrm{a}}$ & 0.13 & $0.47^{\mathrm{a}}$ & 0.08 & $1 \cdot 83^{b}$ & 0.11 \\
\hline Krakow $(n)$ & 42 & & 9 & & 14 & & 11 & & 8 & \\
\hline Energy $(\mathrm{MJ} / \mathrm{d})$ & $7 \cdot 9^{\mathrm{c}}$ & 0.4 & $5 \cdot 8^{\mathrm{a}}$ & 0.8 & $7 \cdot 4^{\mathrm{a}}$ & 0.5 & $7 \cdot 2^{\mathrm{a}}$ & 0.9 & $6 \cdot 3^{\mathrm{a}}$ & $0 \cdot 6$ \\
\hline$\%$ from fat & $36 \cdot 9^{c}$ & 0.8 & $38 \cdot 4^{a}$ & 2.5 & $38 \cdot 9^{a}$ & 1.9 & $33 \cdot 2^{a, b}$ & 1.4 & $29 \cdot 0^{\mathrm{b}}$ & 1.9 \\
\hline$\% \mathrm{E}$ as SFA & $13 \cdot 0^{a, c}$ & 0.5 & $15 \cdot 0^{\mathrm{a}}$ & 0.9 & $11 \cdot 7^{\mathrm{b}}$ & 0.7 & $10 \cdot 5^{b}$ & 0.9 & $9 \cdot 2^{\mathrm{b}}$ & $1 \cdot 1$ \\
\hline$\% \mathrm{E}$ as MUFA & $14 \cdot 6^{\mathrm{d}}$ & 0.4 & $14 \cdot 9^{a, b}$ & $1 \cdot 3$ & $19 \cdot 0^{\mathrm{b}}$ & 1.4 & $14 \cdot 1^{\mathrm{a}}$ & 0.7 & $11.6^{\mathrm{a}}$ & $1 \cdot 1$ \\
\hline
\end{tabular}


Table 4. Continued

\begin{tabular}{|c|c|c|c|c|c|c|c|c|c|c|}
\hline & \multicolumn{2}{|c|}{ Baseline } & \multicolumn{2}{|c|}{ HSFA } & \multicolumn{2}{|c|}{ HMUFA } & \multicolumn{2}{|c|}{ LF } & \multicolumn{2}{|c|}{$\mathrm{LF} n-3$} \\
\hline & Mean & SEM & Mean & SEM & Mean & SEM & Mean & SEM & Mean & SEM \\
\hline$\% \mathrm{E}$ as PUFA & $6 \cdot 5^{\mathrm{b}, \mathrm{c}}$ & 0.4 & $6 \cdot 2^{\mathrm{a}}$ & 0.6 & $5 \cdot 9^{a}$ & 0.3 & $6 \cdot 3^{a}$ & 0.7 & $5 \cdot 8^{a}$ & 0.6 \\
\hline$\% \mathrm{E}$ as $\mathrm{CHO}$ & $43 \cdot 6^{\mathrm{a}, \mathrm{b}}$ & 1.0 & $43 \cdot 2^{a}$ & $2 \cdot 6$ & $42 \cdot 7^{\mathrm{a}}$ & $2 \cdot 0$ & $48 \cdot 3^{\mathrm{a}}$ & 1.9 & $45 \cdot 7^{\mathrm{a}}$ & 3.4 \\
\hline$\% \mathrm{E}$ as protein & $17 \cdot 6^{\mathrm{a}, \mathrm{b}, \mathrm{c}}$ & 0.6 & $17 \cdot 9^{\mathrm{a}, \mathrm{b}}$ & $1 \cdot 1$ & $16 \cdot 4^{\mathrm{a}}$ & 0.8 & $17 \cdot 6^{a, b}$ & 1.2 & $22 \cdot 7^{\mathrm{b}}$ & 2.4 \\
\hline$\%$ E as alcohol & $1 \cdot 6^{\mathrm{b}}$ & 0.5 & $0^{\mathrm{a}}$ & 0 & $1 \cdot 2^{\mathrm{a}}$ & 0.6 & $0.3^{\mathrm{a}}$ & 0.3 & $1.9^{\mathrm{a}}$ & $1 \cdot 1$ \\
\hline Total EPA and DHA $(\mathrm{g} / \mathrm{d}) \dagger$ & $0.36^{a, b, c}$ & 0.14 & $0.43^{\mathrm{a}}$ & 0.38 & $0.24^{a}$ & 0.16 & $0.71^{a}$ & 0.50 & $1.48^{a}$ & 0.13 \\
\hline$n$ & 23 & & 5 & & 7 & & 7 & & 4 & \\
\hline Uppsala $(n)$ & 45 & & 12 & & 13 & & 11 & & 9 & \\
\hline Energy (MJ/d) & $8 \cdot 2^{\mathrm{a}}$ & 0.4 & $9 \cdot 9^{a}$ & 0.8 & $8 \cdot 6^{\mathrm{a}}$ & 0.6 & $8 \cdot 3^{a}$ & 0.6 & $8 \cdot 3^{\mathrm{a}}$ & 0.5 \\
\hline$\%$ E from fat & $32 \cdot 4^{\mathrm{a}, \mathrm{b}}$ & 0.7 & $42 \cdot 3^{\mathrm{a}}$ & 1.6 & $41 \cdot 0^{\mathrm{a}, \mathrm{c}}$ & 1.4 & $33.9^{\mathrm{b}}$ & $1 \cdot 7$ & $34 \cdot 6^{\mathrm{b}, \mathrm{c}}$ & $2 \cdot 1$ \\
\hline$\% \mathrm{E}$ as SFA & $13 \cdot 0^{\mathrm{a}, \mathrm{c}}$ & 0.4 & $20 \cdot 3^{\mathrm{a}}$ & 0.8 & $11.0^{\mathrm{b}}$ & 0.2 & $9.9^{\mathrm{b}}$ & 0.7 & $10 \cdot 4^{b}$ & 0.5 \\
\hline$\%$ E as MUFA & $12 \cdot 1^{\mathrm{a}}$ & 0.3 & $13 \cdot 6^{a}$ & 0.6 & $21 \cdot 3^{b}$ & 1.0 & $15 \cdot 2^{\mathrm{a}}$ & 0.8 & $15 \cdot 7^{\mathrm{a}}$ & $1 \cdot 1$ \\
\hline$\%$ as PUFA & $5 \cdot 0^{\mathrm{a}}$ & 0.2 & $6 \cdot 3^{\mathrm{a}}$ & 0.3 & $7 \cdot 4^{\mathrm{a}}$ & 0.5 & $7 \cdot 5^{\mathrm{a}}$ & 0.4 & $6 \cdot 8^{\mathrm{a}}$ & 0.5 \\
\hline$\% \mathrm{E}$ as $\mathrm{CHO}$ & $49 \cdot 6^{d}$ & 0.9 & $42 \cdot 9^{\mathrm{a}}$ & $1 \cdot 7$ & $44 \cdot 2^{a, b}$ & 1.0 & $48 \cdot 7^{b}$ & $1 \cdot 2$ & $48 \cdot 8^{b}$ & 2.5 \\
\hline$\% \mathrm{E}$ as protein & $16 \cdot 2^{b}$ & 0.4 & $14 \cdot 2^{\mathrm{a}}$ & 0.5 & $13.9^{\mathrm{a}}$ & 0.8 & $15 \cdot 8^{a}$ & 0.4 & $15 \cdot 5^{\mathrm{a}}$ & 0.7 \\
\hline$\%$ E as alcohol & $1 \cdot 7^{\mathrm{a}, \mathrm{b}}$ & 0.4 & $0.7^{\mathrm{a}}$ & 0.4 & $0.9^{a}$ & 0.7 & $1 \cdot 2^{\mathrm{a}}$ & 0.6 & $1 \cdot 1^{a}$ & 0.4 \\
\hline Total EPA and DHA $(\mathrm{g} / \mathrm{d})$ & No data & & No data & & No data & & No data & & No data & \\
\hline
\end{tabular}

HSFA, high-SFA; CHO, carbohydrate; HMUFA, high-MUFA; LF, low-fat; LFn-3, low-fat + DHA + EPA; \%E, percentage energy; CHO, carbohydrate.

$\mathrm{a}, \mathrm{b}, \mathrm{c}, \mathrm{d}$ Mean values within a row with unlike superscript letters were significantly different $(P<0.05)$

${ }^{*}$ Differences between centres were assessed by repeated-measures analysis using a mixed general linear model.

†Fatty acid compositional breakdown is not available for all subjects due to differences in country-specific analysis programs, so $n$ available for this measure is indicated.

other three diets. In the Dublin and Cordoba centres, diet HMUFA was also significantly greater in $\% \mathrm{E}$ from SFA than diet $\mathrm{LF}$ and/or diet LFn-3. In all centres except the Krakow centre, \%E from MUFA was significantly greater in diet HMUFA compared with all other diets. In the Krakow centre, although \%E from MUFA was greater in diet HMUFA than diet HSFA, this difference did not reach the level of statistical significance. In the Dublin and Cordoba centres, \%E from MUFA was significantly greater in diet HSFA compared with diets LF and LFn-3. \%E from PUFA was similar across all four diets, with the exception of the Reading and Maastricht centres, for which diet HMUFA had significantly greater $\% \mathrm{E}$ from PUFA than diet LF and $\mathrm{LF} n-3$, respectively. \% $\mathrm{E}$ from $\mathrm{CHO}$ was consistently greater in diets LF and LFn-3 compared with diets HSFA and HMUFA and these differences were statistically significant in five out of the eight centres. Finally, all centres achieved isoenergetic diets with the exception of the Dublin centre, in which diet HMUFA had significantly greater energy than diet LFn-3 (10.9 and 6.5 MJ/d, respectively).

\section{Compliance and under-reporting}

All volunteers on diets LF and LF $n-3$ reported $\geq 85 \%$ compliance to the capsules. Schofield equations were used to estimate BMR. The Goldberg cut-off for energy intake (BMR of 1.05) was used to identify under-reporters ${ }^{(8)}$. There were no significant differences in the level of under-reporting between diet groups or at any of the time points of dietary assessment. Body weight was significantly reduced over time on diets LF and LFn-3 $(P<0 \cdot 0005)$.

\section{Discussion}

The purpose of the present report was to describe and evaluate a food-exchange model used to create four diets distinct in fat quantity and quality, in an intervention study carried out in free-living volunteers across Europe.
The results indicate that the food-exchange model was successful. The compositional objectives were largely achieved. This food-exchange model enabled the creation of two diets (HSFA and HMUFA) that were significantly different in terms of $\% \mathrm{E}$ from fat than the other two diets (LF and LFn-3). This was achieved by the use of $\mathrm{CHO}$ exchanges, which significantly increased $\% \mathrm{E}$ from $\mathrm{CHO}$ in the low-fat diets compared with the higher-fat diets. The second objective was also fulfilled as diet HSFA had significantly greater $\% \mathrm{E}$ from SFA compared with the other three diets, whereas diet HMUFA had significantly greater $\%$ E from MUFA than the other diets. Similarly, the third objective was met with significantly greater long-chain $n$-3 PUFA intakes in the LFn-3 diet group.

At baseline, there were no significant differences in the nutrient composition of the four groups, whereas at both the mid and end of the intervention periods the four diets were distinct in their dietary fat composition. The dietary change instigated during the intervention period was maintained throughout the intervention period as no significant differences in the levels of key nutrients were found between the mid and end of intervention periods.

The distinct differences in baseline dietary intake between centres highlight the challenge which was set; to change the habitual diets of volunteers at all centres with the use of a single food-exchange model. This highlights the novel aspect of the present work. Previous reports have shown replacement of SFA for MUFA is possible in a UK population, when at least one meal per $\mathrm{d}$ is provided alongside additional study foods ${ }^{(1,2)}$. The present study has shown that dietary fat alteration also can be achieved through the sole use of study foods when incorporated by volunteers themselves into desirable meal formats. Furthermore, these results show that this strategy can be used across populations with variations in habitual dietary intakes. Overall the $\% \mathrm{E}$ from fat was significantly different between the high- and low-fat diets. However, in three centres this difference did not reach the level of statistical significance at the week 12 dietary assessment (Oslo, Krakow, Uppsala). Notably, at mid-intervention the 
Uppsala and Oslo centres did achieve significant distinction in $\% \mathrm{E}$ from fat between these diets. The Uppsala data provide an important insight into the usefulness of the food-exchange model and highlight the challenges encountered when habitual diets differed across the intervention population. The foodexchange model described depended on the ability of volunteers to undertake fat- $\mathrm{CHO}$ exchanges in order to achieve $\% \mathrm{E}$ from fat targets in the low-fat diets. As CHO formed a large part of the habitual diets of volunteers in the Uppsala centre $(49.6 \% \mathrm{E})$ before intervention, further increases in this macronutrient proved difficult to achieve in addition to difficulties in reducing fat further. Thus, at the end of the intervention period, although $\% \mathrm{E}$ from fat was greater in diet HMUFA than the LFn-3 diet, these differences in $\% \mathrm{E}$ from fat did not reach the level of statistical significance. However, a statistically significant distinction in \% $\mathrm{E}$ from $\mathrm{CHO}$ between the high-fat and low-fat diets was not an essential output of the model. In the Dublin and Reading centres, differences in $\% \mathrm{E}$ from $\mathrm{CHO}$ between the high- and low-fat diets were observed but these too did not reach the level of statistical significance. However, these centres achieved target differences in $\% \mathrm{E}$ from fat between diet groups. Key to this was the ability of these centres, in contrast to Uppsala, to further increase $\mathrm{CHO}$ intake in the low-fat diets above their baseline levels.

All centres achieved the second objective (\%E from SFA in diet HSFA was significantly greater than the other three diets), irrespective of baseline intake. In addition, in the Cordoba and Dublin centres, diet HMUFA had significantly greater $\% \mathrm{E}$ from SFA than the low-fat diets. Although this did not reach statistical significance in the other centres, most displayed a similar trend. This highlights a difficulty in the targeted reduction of SFA alongside the maintenance of a high-fat, high-MUFA diet, which has been reported previously ${ }^{(2)}$. In the Cordoba centre, however, the data suggest the significant difference in $\% \mathrm{E}$ from SFA reported between the HMUFA diet and low-fat diets was due instead to low $\% \mathrm{E}$ from SFA intakes within the low-fat diet groups, reflective of habitual dietary intake, rather than a problem with reducing SFA in the HMUFA diet. Critically, these data do not indicate a fault in the model as $\% \mathrm{E}$ from SFA remained significantly greater in diet HSFA compared with the other diets.

All centres also achieved a level of $\% \mathrm{E}$ from MUFA in diet HMUFA that was greater than the other diets. This reached statistical significance in all centres except the Krakow centre, where the difference was not statistically significant. This difficulty again is likely to be associated with habitual dietary intake. The $\% \mathrm{E}$ from MUFA intake at baseline for this centre was significantly greater than all centres except Cordoba. This highlights the difficulties associated with the targeted substitution of a specific fatty acid subclass with another, whilst maintaining a high fat intake. Furthermore, in the Dublin and Cordoba centres, \%E from MUFA was significantly greater in diet HSFA compared with the lower-fat diets, underlining the difficulty of targeted subclass manipulation alongside control of fat quantity.

PUFA levels were maintained at similar levels across all diets, although diet HMUFA tended to have greater levels compared with the low-fat diets, reaching statistical significance for the Reading and Maastricht centres. At baseline, these centres had the lowest intake of $\% \mathrm{E}$ from MUFA. To substantially increase $\% \mathrm{E}$ from MUFA, the use of food sources, for example, hazelnuts, in addition to the study foods provided, were actively encouraged at these centres. This allowed the successful distinction of diet HMUFA in terms of MUFA content but concurrently is likely to have increased PUFA intake. An unavoidable change in the composition of the mayonnaise product used in diet HMUFA, as detailed below, may also explain the increased $\% \mathrm{E}$ from PUFA in the HMUFA diet.

\section{Logistic challenges}

Although the results show the strategy for dietary manipulation was successful, certain problems were encountered. Provision of adequate refrigerated storage for a period of up to 18 months was required for volumes of up to $270 \mathrm{~kg}$ spread, $180 \mathrm{~kg}$ baking fat and room temperature storage for $1254 \mathrm{~kg}$ biscuits, $208 \mathrm{~kg}$ oil and $100 \mathrm{~kg}$ mayonnaises per centre. Logistics for the distribution of the various products to all centres was highly complex. Required food volumes had to be individually calculated per centre and per cohort, based on their number of volunteers (and their study food preferences).

\section{Food production challenges}

Difficulties also arose in the design of the study foods, in terms of their ideal theoretical nutritional composition $v$. a useable composition with satisfactory organoleptic properties. A major difficulty arose in the formulation of an oil product for diet HSFA. To fulfil the requirements of the model this product had to be based largely on SFA. Originally a suitable bottled liquid product was produced, but this could not be repeated as seasonal temperature changes resulted in this product solidifying during production of subsequent batches. Thus, the product had to be packaged in a tub format, with improvements in colour and flavour to improve volunteer acceptability. Another problem was a change in supplier of the mayonnaise product, as the factory responsible for production of the original products went into liquidation. Unfortunately the second supplier could not produce products to match the exact nutrient composition of the first. As a result the mayonnaise used in cohort 2, for diet HMUFA, had lower levels of MUFA and higher levels of PUFA than originally planned (Table 3).

Key to the overall success of this food-exchange model was the flexibility incorporated within its design. Provision of foods other than those which were essential within the food-exchange model enabled this achievement. For example, a mayonnaise product was provided for the low-fat diets. This was not a specific tool within the model to alter dietary composition, but as the intervention study was completed in summer months when salad cream and mayonnaise can be consumed in large amounts, a suitable alternative was provided. Baking fat was also provided for diets HSFA and HMUFA (Table 3) to allow volunteers to prepare their own cakes or biscuits if desired. However, to increase the flexibility of the LIPGENE model for use in other population groups and further optimise its use, additional modifications could be incorporated. For application of such an exchange model in ethnic minority populations whom have specific eating habits, additional modification could be implemented. For example, spreads are 
not a usual component of the Asian population's habitual diet so the use of these could be omitted and the equivalent quantity of fat consumed in the form of oil. Different snack foods could also be produced with the study baking fats which would be acceptable to the population studied. Inevitably a prescribed food-exchange model has limitations when used for groups with distinct dietary habits, yet the present study demonstrates that the LIPGENE food-exchange model allowed sufficient flexibility to achieve the nutrient targets in the pan-European population studied, with the potential of further refinements for other population groups. Indeed, a modification of this food-exchange model has been adopted successfully in a dietary intervention study based in the $\mathrm{UK}^{(9)}$.

In conclusion, a robust, flexible food-exchange model was developed and implemented successfully in the LIPGENE pan-European intervention study. The main objective, to design four diets distinct in fat quality and quantity, was achieved. This food-exchange model has the flexibility to be implemented in future studies designed to investigate the effects of diet in free-living populations with varying habitual dietary intakes.

\section{Acknowledgements}

We gratefully thank all the volunteers for their time and motivation. We thank the research teams at each centre for their enthusiasm and dedication. We also thank Dr Rachel Gitau for her help with the food-exchange model development and Cecilia Mallmann from CIC-Marseille for her contribution to the implementation of the diets. This research was supported by funding from the European Commission, Framework Programme 6 as part of the LIPGENE project (FOOD-CT-2003-505944). Funding was also granted from Health and Rehabilitation, Johan Throne Holst Foundation for Nutrition Research and Helse $\emptyset_{\text {st }}$ in Norway.

No authors have any conflict of interests.

J. A. L. and S. M. developed the food-exchange model. S. M. and D. I. S. verified the food-exchange model. H. M. R., J. A. L., C. A. D., E. E. B, W. H. M. S., B. K. and J. L.-M. contributed to the design of the LIPGENE dietary intervention study. J. U. and S. V. were involved with the formulation and supply of the study foods. D. I. S., A. C. T., H. L. G., O. H., C. D., R. G., D. S. and M. M.-M. were involved with the implementation of the dietary strategy. D. I. S. and J. A. L. prepared the manuscript with comments taken from H. M. R., A. C. T., S. M., J. U., S. V., H. L. G., C. A. D., E. E. B., W. H. M. S., B. K., O. H., C. D., R. G. and J. L.-M. The LIPGENE human dietary intervention study was coordinated by H. M. R.

D. I. S., A. C. T. and S. M. contributed equally to the present study.

\section{References}

1. Knapper JME, Tredger JA, Webb D, Culverwell C, Faulkner W, Roche H \& Williams CM (1996) Substitution of dietary monounsaturated fatty acids for saturated fatty acids in a free-living population: a feasibility study. J Hum Nutr Diet 9, 273-282.

2. Nydahl MC, Smith RD, Kelly CNM, Fielding BA \& Williams CM (2003) Achievement of dietary fatty acid intakes in longterm controlled intervention studies: approach and methodology. Public Health Nutr 6, 31-40.

3. Tierney AC, Lovegrove JA, Lovdal Gulseth, et al. (2007) LIPGENE dietary intervention: cohort details and study design. Proc Nutr Soc 66, 33A.

4. Henderson L, Gregory J, Irving K \& Swan G (2003) The National Diet and Nutrition Survey: Adults Aged 19-64 Years. London: H.M. Stationery Office.

5. Department for Environment, Food and Rural Affairs (2000) DEFRA Economics \& Statistics - National Food Survey 2000. http://statistics.defra.gov.uk/esg/publications/nfs/2000/default.asp

6. Harrington KE, Robson PJ, Kiely M, Livingstone MB, Lambe J \& Gibney MG (2001) The North/South Ireland Food Consumption Survey: survey design and methodology. Public Health Nutr 4, 1037-1042.

7. Roche HM, Zampelas A, Knapper JME, et al. (1998) Effect of long-term olive oil dietary intervention on postprandial triacylglycerol and factor VII metabolism. Am J Clin Nutr 68, 552-560.

8. Black AE (2000) The sensitivity and specificity of the Goldberg cut-off for EI:BMR for identifying diet reports of poor validity. Eur J Clin Nutr 54, 395-404.

9. Moore C, Farrant H, Gitau R, Goff L, Griffin M, Lewis F \& Lovegrove J (2008) The RISCK food exchange model: a dietary strategy to alter the amount and composition of fat and carbohydrate in free-living individuals. Proc Nutr Soc (In the Press). 
Appendix 1. Nutrient composition of study foods $(\mathrm{g} / 100 \mathrm{~g})^{\star}$

\begin{tabular}{|c|c|c|c|c|c|c|c|c|c|c|c|c|c|c|c|c|}
\hline & $\begin{array}{c}\text { Energy } \\
(\mathrm{MJ})\end{array}$ & $\begin{array}{l}\text { Fat } \\
\text { (g) }\end{array}$ & $\begin{array}{l}\text { Protein } \\
\text { (g) }\end{array}$ & $\begin{array}{c}\mathrm{CHO} \\
\text { (g) }\end{array}$ & $\begin{array}{l}\text { Sugar } \\
\text { (g) }\end{array}$ & $\begin{array}{c}\text { SFA } \\
\text { (g) }\end{array}$ & $\begin{array}{l}\text { MUFA } \\
(\mathrm{g})\end{array}$ & $\begin{array}{l}\text { PUFA } \\
\text { (g) }\end{array}$ & $\begin{array}{l}8: 0 \\
(\mathrm{~g})\end{array}$ & $\begin{array}{c}10: 0 \\
\text { (g) }\end{array}$ & $\begin{array}{c}12: 0 \\
(\mathrm{~g})\end{array}$ & $\begin{array}{c}14: 0 \\
(\mathrm{~g})\end{array}$ & $\begin{array}{c}16: 0 \\
\text { (g) }\end{array}$ & $\begin{array}{c}18: 0 \\
(\mathrm{~g})\end{array}$ & $\begin{array}{c}18: 1 \\
(\mathrm{~g})\end{array}$ & $\begin{array}{c}18: 2 n-6 \\
(\mathrm{~g})\end{array}$ \\
\hline \multicolumn{17}{|l|}{ Diet HSFA } \\
\hline Honey flapjack & $2 \cdot 23$ & $31 \cdot 7$ & $7 \cdot 7$ & $57 \cdot 3$ & $18 \cdot 8$ & 14.4 & $8 \cdot 8$ & 4.5 & 0.3 & 0.3 & 3.4 & 1.3 & 3.4 & $2 \cdot 9$ & $7 \cdot 2$ & $4 \cdot 1$ \\
\hline Muesli cookie & 1.79 & $19 \cdot 3$ & 5.9 & $60 \cdot 4$ & $32 \cdot 2$ & 9.2 & $5 \cdot 0$ & $3 \cdot 6$ & 0.3 & 0.3 & $3 \cdot 1$ & $1 \cdot 2$ & $2 \cdot 7$ & $2 \cdot 4$ & $5 \cdot 5$ & $4 \cdot 3$ \\
\hline Spread & 2.96 & 80 & 0 & 0 & 0 & 39.4 & $20 \cdot 7$ & $19 \cdot 8$ & 0.6 & 0.6 & 9.5 & 3.3 & $11 \cdot 7$ & $12 \cdot 9$ & $20 \cdot 1$ & $16 \cdot 7$ \\
\hline Spread (LS) & 2.96 & 80 & 0 & 0 & 0 & 39.4 & $20 \cdot 7$ & $19 \cdot 8$ & 0.7 & 0.7 & 9.6 & 3.3 & $11 \cdot 7$ & $12 \cdot 8$ & $20 \cdot 1$ & $16 \cdot 8$ \\
\hline Oil replacement & 3.69 & 99.6 & 0 & 0 & 0 & $48 \cdot 2$ & 33.4 & $17 \cdot 8$ & 0.7 & 0.7 & $10 \cdot 9$ & 3.9 & $15 \cdot 9$ & $16 \cdot 1$ & 32.5 & $15 \cdot 0$ \\
\hline Baking fat & 3.66 & 99 & 0 & 0 & 0 & 47.9 & $33 \cdot 1$ & $17 \cdot 7$ & 0.8 & 0.8 & $11 \cdot 1$ & 3.9 & 14.9 & $15 \cdot 7$ & $32 \cdot 4$ & $15 \cdot 4$ \\
\hline \multicolumn{17}{|l|}{ Diet HMUFA } \\
\hline Honey flapjack & $2 \cdot 23$ & $31 \cdot 7$ & $7 \cdot 7$ & $57 \cdot 3$ & $18 \cdot 8$ & 7.2 & $15 \cdot 2$ & $5 \cdot 3$ & 0.3 & 0.3 & $3 \cdot 1$ & $1 \cdot 2$ & 3.4 & $3 \cdot 1$ & $7 \cdot 4$ & 4.5 \\
\hline Muesli cookie & 1.79 & $19 \cdot 3$ & 5.9 & $60 \cdot 4$ & $32 \cdot 2$ & $5 \cdot \overline{3}$ & 8.5 & 4.0 & 0.2 & 0.2 & 1.6 & $0 . \overline{7}$ & $1 \cdot 8$ & 0.9 & $7 \cdot 8$ & 4.2 \\
\hline Spread & $2 \cdot 96$ & 80 & 0 & 0 & 0 & $15 \cdot 3$ & $47 \cdot 8$ & $16 \cdot 7$ & 0.1 & 0.1 & 1.8 & 0.7 & 7.9 & 4.0 & $46 \cdot 7$ & $14 \cdot 1$ \\
\hline Spread (LS) & 2.96 & 80 & 0 & 0 & 0 & $15 \cdot 3$ & 47.9 & $16 \cdot 7$ & 0.1 & 0.1 & 1.8 & 0.7 & 7.9 & 4.0 & $46 \cdot 8$ & $14 \cdot 1$ \\
\hline Oil & 3.70 & 100 & 0 & 0 & 0 & $15 \cdot 6$ & 74.4 & 9.9 & 0 & 0 & 0 & 0 & $12 \cdot 0$ & 2.9 & 73.0 & 9.3 \\
\hline Baking fat & 3.66 & 99 & 0 & 0 & 0 & $19 \cdot 0$ & 49.5 & $30 \cdot 3$ & 0.2 & 0.2 & $2 \cdot 4$ & 0.9 & $9 \cdot 3$ & $5 \cdot 3$ & 48.4 & $25 \cdot 9$ \\
\hline Mayonnaise (C1) & 3.02 & 81.4 & 0.7 & 0 & 0 & $12 \cdot 7$ & $60 \cdot 7$ & 7.6 & 0 & 0 & 0 & 0 & 9.3 & 2.4 & 59.1 & 7.0 \\
\hline Mayonnaise (C2) & 2.97 & $79 \cdot 1$ & $1 \cdot 1$ & 1.3 & 1.3 & $6 \cdot 2$ & $50 \cdot 0$ & 22.9 & 0 & 0 & 0 & 0 & 4.0 & 1.4 & $48 \cdot 3$ & $16 \cdot 0$ \\
\hline \multicolumn{17}{|l|}{ Diet LF and LF $n-3$} \\
\hline Honey flapjack & $2 \cdot 23$ & $31 \cdot 7$ & $7 \cdot 7$ & $57 \cdot 3$ & $18 \cdot 8$ & $7 \cdot 2$ & $15 \cdot 2$ & $5 \cdot 3$ & 0.3 & 0.3 & $3 \cdot 1$ & 1.2 & 3.4 & $3 \cdot 1$ & 7.4 & 4.5 \\
\hline Muesli cookie & 1.79 & $19 \cdot 3$ & 5.9 & 60.4 & $32 \cdot 2$ & $5 \cdot 3$ & 8.5 & 4.0 & 0.2 & 0.2 & 1.6 & 0.7 & 1.8 & 0.9 & $7 \cdot 8$ & 4.2 \\
\hline Spread & 1.03 & 27.9 & 0 & 0 & 0 & $6 \cdot 1$ & 14.4 & 7.5 & 0.1 & 0.1 & 0.9 & 0.3 & $2 \cdot 7$ & $1 \cdot 7$ & 14.0 & $6 \cdot 3$ \\
\hline Spread (LS) & 1.03 & $27 \cdot 9$ & 0 & 0 & 0 & $6 \cdot 1$ & 14.4 & 7.5 & 0.7 & 0.1 & 0.8 & 0.3 & $2 \cdot 8$ & 1.7 & $14 \cdot 1$ & 6.3 \\
\hline Oil & $3 \cdot 70$ & 100 & 0 & 0 & 0 & $11 \cdot 0$ & 55.9 & 33.0 & 0 & 0 & 0.1 & 0.1 & $7 \cdot 2$ & $2 \cdot 6$ & $54 \cdot 6$ & $27 \cdot 6$ \\
\hline Mayonnaise (C1) & 1.13 & $26 \cdot 4$ & 1.9 & $6 \cdot 8$ & 5.7 & $3 \cdot 2$ & $14 \cdot 3$ & 8.5 & 0 & 0 & 0.1 & 0 & 1.8 & 0.7 & 13.5 & $7 \cdot 0$ \\
\hline Mayonnaise (C2) & 1.24 & 29.8 & 0.7 & $6 \cdot 7$ & $2 \cdot 2$ & $2 \cdot 7$ & $18 \cdot 7$ & $8 \cdot 3$ & 0 & 0 & 0 & 0.1 & 1.7 & 0.6 & $18 \cdot 1$ & $5 \cdot 7$ \\
\hline
\end{tabular}

CHO, carbohydrate; HSFA, high-SFA; LS, low-salt; HMUFA, high-MUFA; C1, foods used in cohort 1; C2, foods used in cohort 2; LF, low-fat; LF $n$-3, low-fat + DHA + EPA. *Diet HSFA had an oil replacement product because a liquid oil with the required SFA composition was not technologically viable. Mayonnaise and baking products for diet HSFA and diets LF and LFn-3, respectively, were not
required. 